\title{
Numerical Assessment of Fibre Inclusion in Load Transfer Platform for Pile-Supported Embankments over Soft Soil
}

\author{
Liet Chi Dang ${ }^{1}$, Cong Chi Dang ${ }^{2}$, Hadi Khabbaz ${ }^{3}$ and Behzad Fatahi ${ }^{4}$
}

\footnotetext{
${ }^{1}$ Ph.D. Candidate, School of Civil and Environmental Engineering, University of Technology Sydney (UTS), Ultimo, NSW 2007, Australia. E-mail: lietchi.dang@student.uts.edu.au

${ }^{2}$ Senior Civil Engineer, Department of Environment and Natural Resources, Hau Giang province, 910000, Viet Nam. E-mail: chicongct1912@gmail.com

${ }^{3}$ Associate Professor of Geotechnical Engineering, School of Civil and Environmental Engineering, University of Technology Sydney (UTS), 15 Broadway Ultimo NSW 2007, Australia. E-mail: hadi.khabbaz@uts.edu.au

${ }^{4}$ Senior Lecturer in Geotechnical Engineering, School of Civil and Environmental Engineering, University of Technology Sydney (UTS), 15 Broadway Ultimo NSW 2007, Australia. E-mail: behzad.fatahi@uts.edu.au
}

\begin{abstract}
This study presents the results of a numerical investigation in the performance of natural fibre reinforced load transfer platform (NFRLTP) for pile supported embankment construction over soft soil. A numerical analysis based on finite element method (FEM) was carried out on an NFRLTP pile-supported embankment in a two-dimensional plane strain condition. The effects of natural fibre inclusion in the load transfer platform on the stress transfer mechanism, generation and dissipation of excess pore water pressure have been analyzed and discussed in detail. The findings indicate that natural fibre reinforced soil as a load transfer platform facilitated the load transfer process from the embankment to piles, while decreases the intensity of load transferred to soft soil, the excess pore water pressure and the overall settlement.
\end{abstract}

\section{INTRODUCTION}

Many courtiers are experiencing a dramatic increase in development of essential infrastructure including roads and rail networks. Embankment construction is one of the most common methods used to provide better ground supports for roads and railways. However, due to lack of readily available strong lands for such transport infrastructure projects, many embankments should be founded on soft ground. This practice is highly risky because soft ground has low bearing capacity, insufficient shear strength and high compressibility. Therefore, in order to ensure the stability of embankment during construction process and long term services, appropriate ground improvement techniques are needed to be adopted in enhancing the engineering properties of soft soil or even in order to transfer embankment and traffic loads to deeper and stiffer soil stratum.

Several ground improvement techniques can be applied to improve soft soil properties to support embankment construction such as preloading with vertical drain application (ParsaPajouh et al. 2015), excavating the existing soft ground and substituting it with high shear strength and bearing capacity backfill soil, reducing embankment load by using lightweight fill material, constructing in stages and leaving time for consolidation, improving soft ground underneath embankment by chemical treatment (Nguyen et al. 2014), stone columns (Fatahi 
et al. 2012) and geosynthetic-reinforced and pile supported earth platform (Han \& Gabr 2002; Liu et al. 2007). All these ground improvement techniques have their benefits and drawbacks based on many influential factors including actual site conditions, construction time, and construction purposes of embankment. In this investigation, the authors are mainly concerned with natural fibre reinforced embankment as load transfer platform over reinforced concrete piles.

It is known that the fibre reinforced load transfer platform has similar functions as geosynthetic-reinforced platform, which includes preventing differential settlement of embankment constructed over soft subgrade, differential settlement between new embankment and an existing embankment, large lateral pressure and movement, slope instability as well as bearing capacity failures, (Han \& Gabr 2002). The load transfer platform can be composed of gravel, reinforced concrete slab, cemented soil, lime treated soil (Okyay \& Dias 2010; Dang et al. 2015), and coconut coir fibre-lime treated soil introduced by Sivakumar et al. (2008) and Anggraini et al. (2015). According to several recent studies (e.g. Anggraini et al. 2015; Okyay \& Dias 2010) fibre-lime treated soil can be successfully adopted under structure foundations so as to provide uniformly distributed settlement. In addition, their research presented that chemically treated soil results in enhancement of tensile strength and shear resistance. However, a number of investigators (e.g. Cai et al. 2006; Okyay \& Dias 2010) noted that lime or cement treated soil would exhibit brittle failure behavior. Such brittle behavior results in a rapid and great loss of post-peak strength when failure occurs. Nevertheless, Fatahi et al. (2013) reported that adding geofibre-cement treated soft clay significantly contributed to increase in the strength and reduction of shrinkage potential. Moreover, addition of fibre contributes a remarkable increase in the tensile strength, the residual strength, while changing the behavior of the cement treated soft clay from brittle to more ductile behavior (Fatahi et al. 2012).

In order to have a better understanding of embankment behavior built on soft soil, a twodimensional numerical simulation of a case history was carried out in this study. The findings of this numerical study are presented, and comprehensive discussion related to settlement, the load transfer mechanism consisting of stress reduction ratio and stress concentration ratio is presented. The variation of the excess pore water pressure in the soft soil stratum is also presented.

\section{CASE STUDY}

FIG. 1 displays a schematic diagram of the embankment supported on piles, considered in this investigation. While the entire embankment cross section is shown in FIG. 1, due to symmetry only half of the embankment about its center, presented in FIG. 2, is adopted to model in this numerical analysis. As can be seen in FIG. 1, the embankment has $5.6 \mathrm{~m}$ height and $120 \mathrm{~m}$ length with a crest width of $35 \mathrm{~m}$, and its side slopes are $1 \mathrm{~V}: 1.5 \mathrm{H}$. The embankment is made of fill material with a cohesion of $10 \mathrm{kPa}$, a friction angle of $30^{\circ}$, and an average unit weight of $18.5 \mathrm{kN} / \mathrm{m}^{3}$. It is constructed on a $1.5 \mathrm{~m}$ thick coarse-grained fill overlaying a $2.3 \mathrm{~m}$ thick deposit of silty clay. This deposit of silty clay overlies a $10.2 \mathrm{~m}$ thick soft silty clay stratum. Underneath the soft silty clay layer, there is a 2 m thick medium silty clay layer followed by a $9 \mathrm{~m}$ thick sandy silt layer. The ground-water table is located at a depth of $1.5 \mathrm{~m}$ below the ground surface. Details of these soil layers are summarized in Table $1 \& 2$. A coir fibre-lime reinforced load transfer platform of $0.5 \mathrm{~m}$ is placed on the top of piles, which has an effective cohesion and friction angle of $75 \mathrm{kPa}$ and $42^{\circ}$, respectively, an average unit weight of $12.5 \mathrm{kN} / \mathrm{m}^{3}$, a Poisson ratio of 0.32 , a Young's modulus of $51 \mathrm{MPa}$, and tensile strength of $90 \mathrm{kPa}$.

Referring to FIG.1, annulus concrete piles of $1 \mathrm{~m}$ diameter and $16 \mathrm{~m}$ length used to support 
embankment are cast in place with a $120 \mathrm{~mm}$ wall thickness. The $0.5 \mathrm{~m}$ top pile head is casted as solid cylindrical piles. The annulus piles are arranged in square grid pattern with 3.0 $\mathrm{m}$ center to center spacing, giving an area replacement ratio of approximately $8.7 \%$. The construction of embankment is performed in $0.5 \mathrm{~m}$ increment to a height of $5.6 \mathrm{~m}$ over period of 55 days followed by 125 days of waiting period for consolidation after the end of embankment construction.

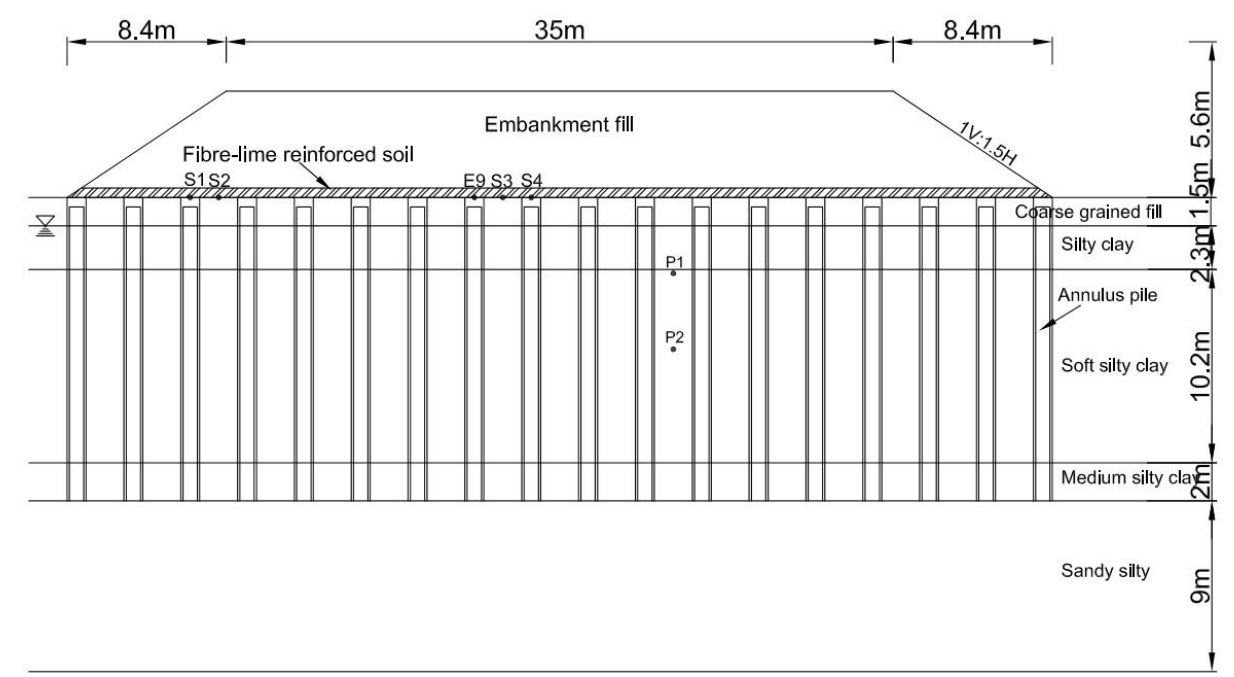

FIG. 1 Cross section of the natural fibre reinforced load transfer platform and pile supported embankment

\section{NUMERICAL MODELING}

\section{D Finite Element Model}

2D plane strain model was built using commercial finite element software PLAXIS V9.02 adopting the equivalent 2D numerical method proposed by Tan et al. ( 2008). The annulus concrete piles were simulated by continuous plane strain walls of $0.26 \mathrm{~m}$ thickness for the top $0.5 \mathrm{~m}$ of piles and $0.11 \mathrm{~m}$ for the rest of the pile length, considering equivalent axial rigidity (EA) and bending rigidity (EI). With regard to the constitutive modeling, the annulus piles were modeled as an isotropic linear elastic material with a Young's modulus of $20 \mathrm{GPa}$, and a Poisson's ratio of 0.2. The fibre-lime reinforced load transfer platform, embankment fill, coarse-grain fill were simulated using a linear elastic-perfectly plastic model with MohrCoulomb failure criterion. The Mohr-Coulomb material model requires Young's modulus, $\mathrm{E}_{\mathrm{s}}$, Poisson's ratio, $v$, effective cohesion c', angle of internal friction, $\varphi^{\prime}$, and dilation angle, $\psi$. The four foundation soils shown FIG. 1 were represented by Modified Cam Clay (MCC) material model. The required parameters for the MCC model are slope of the virgin consolidation line, $\lambda$, slope of swelling line, $\kappa$, void ratio at unit pressure, $\mathrm{e}_{1}$, slope of the critical state line, M, and Poisson's ratio, v. A summary of the constitutive model parameters is given in Table 1 and 2.

As mentioned earlier, only half of the embankment is represented in this numerical simulation since the embankment is symmetrical along its centerline. The foundation soil is taken to $25 \mathrm{~m}$ depth from the ground surface overlying a stiff impermeable stratum. The horizontal length of the FEM model is taken to be $78 \mathrm{~m}$, which is almost three times the half width of the embankment base, in order to minimize the boundary influence. All these boundaries are considered to be impermeable, and pore fluid flow is permitted only from the surface.

In this analysis, for the 2D plane strain FEM model, the horizontal displacement at the left 
and right boundaries was not permitted but vertical movement was allowed, whereas both the vertical and horizontal displacements were prevented at the bottom boundary. On one hand, due to the relatively high permeability, the embankment fill, coarse-grained fill were assumed to behave in a drained condition. On the other hand, natural fibre reinforced platform, annulus piles, and other four foundation soils were assumed to act as undrained material. In this analysis, fifteen-node triangular elements with excess pore water pressure degrees of freedom at all nodes were adopted to simulate the foundation soil, while fifteen nodes triangular elements without excess pore water pressure degrees of freedom at all nodes were applied to model the embankment fill and annulus concrete piles.

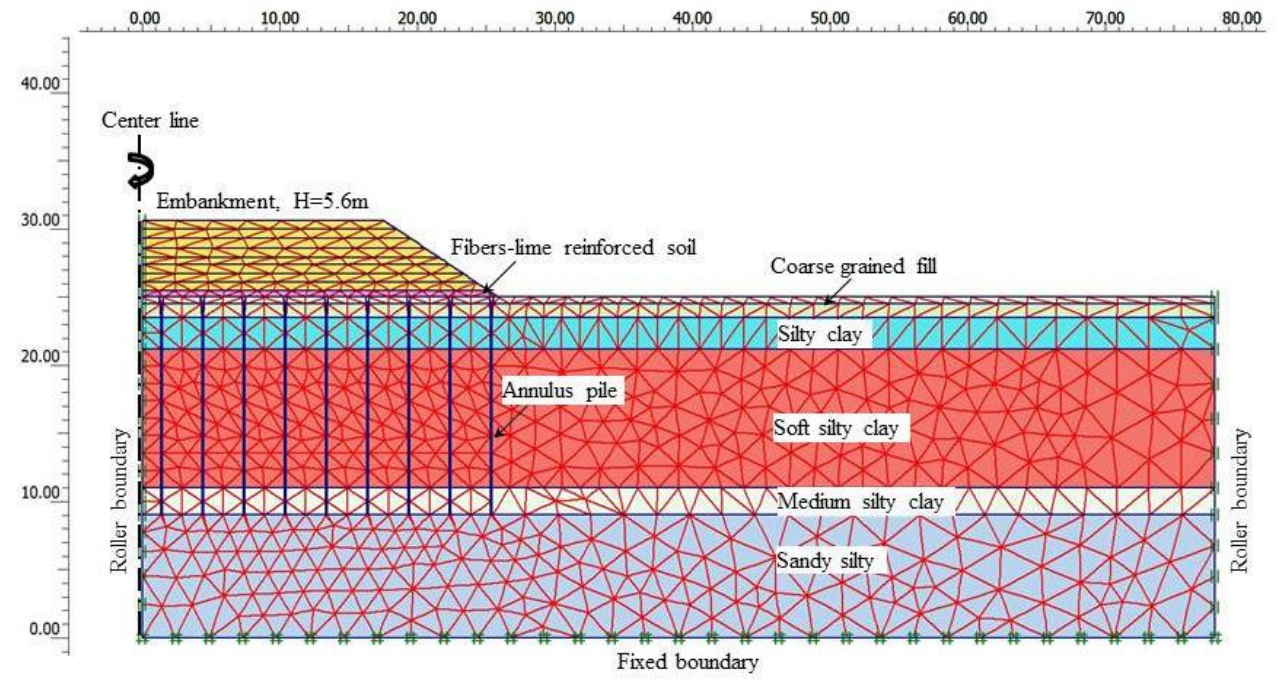

FIG. 2 2D Model adopted for analysis of embankment

Table 1. Material Properties for Mohr-Coulomb Model Used in the FEM Simulation (after Liu et al. 2007; Anggraini et al. 2015)

\begin{tabular}{|c|c|c|c|c|c|c|c|}
\hline Material & $\begin{array}{c}\gamma \\
\left(\mathrm{kN} / \mathrm{m}^{3}\right)\end{array}$ & $\begin{array}{c}\mathrm{E}_{\mathrm{s}} \\
(\mathrm{MPa})\end{array}$ & $\begin{array}{c}\mathrm{c}^{\prime} \\
(\mathrm{kPa})\end{array}$ & $\begin{array}{c}\varphi^{\prime} \\
(\mathrm{deg})\end{array}$ & $\begin{array}{c}\psi \\
(\mathrm{deg})\end{array}$ & $k(\mathrm{~m} /$ day $)$ & $v$ \\
\hline Embankment Fill & 18.5 & 20 & 10 & 30 & 0 & - & 0.3 \\
\hline $\begin{array}{c}\text { Natural fibre-lime- } \\
\text { soil }\end{array}$ & 12.5 & 51 & 75 & 42 & 0 & - & 0.32 \\
\hline Coarse grained fill & 20 & 7 & 15 & 28 & 0 & - & 0.3 \\
\hline Pile & 25 & 20000 & - & - & - & - & 0.2 \\
\hline
\end{tabular}

Table 2. Material Properties for Modified Cam Clay model Used in the FEM Simulation (after Liu et al. 2007)

\begin{tabular}{|c|c|c|c|c|c|c|c|}
\hline Material & $\begin{array}{c}\gamma \\
\left(\mathrm{kN} / \mathrm{m}^{3}\right)\end{array}$ & $\lambda$ & $\kappa$ & $\mathrm{M}$ & $\mathrm{e}_{1}$ & $k(\mathrm{~m} /$ day $)$ & $\nu$ \\
\hline Silty clay & 20 & 0.06 & 0.012 & 1.2 & 0.87 & $8.64 \times 10^{-4}$ & 0.35 \\
\hline Soft silty clay & 17 & 0.15 & 0.03 & 0.95 & 1.79 & $4.32 \times 10^{-4}$ & 0.4 \\
\hline Medium silty clay & 20.5 & 0.05 & 0.01 & 1.1 & 0.88 & $4.32 \times 10^{-4}$ & 0.35 \\
\hline Sandy silt & 20 & 0.03 & 0.005 & 0.28 & 0.97 & $4.32 \times 10^{-3}$ & 0.35 \\
\hline
\end{tabular}

The embankment is constructed in nine lifts including the natural fibre-lime reinforced load transfer platform, which is $0.5 \mathrm{~m}$ thick. During the first step of analysis, all the elements corresponding to fill materials were inactivated and the foundation soil and piles were activated. Then, elements associating with each layer were added one by one in each step 
until the $5.6 \mathrm{~m}$ embankment height was reached over a period of 55 days. In the final step, the fully constructed embankment was left for 125 days for consolidation.

\section{Validation of 2D Finite Element Model}

A full scale load test and a 3-dimensional model of a geogrid-reinforced and pile supported highway embankment with an area replacement ratio of $8.7 \%$ reported by Liu et al. (2007) were used to validate the modeling approach adopted in this study. The simulation procedure in detail for embankment analysis conducted by Liu et al. (2007) in step by step was followed in this research when natural fibre-lime soil was adopted to reinforce load transfer platform. The measured and computed embankment load between piles and foundation soil surface, pore water pressure variation presented by Liu et al. (2007) were compared in FIG. 3-6. The numerical analysis indicates that the equivalent 2D FEM model proposed in this study is suitable for simulating pile supported embankment over soft soil.

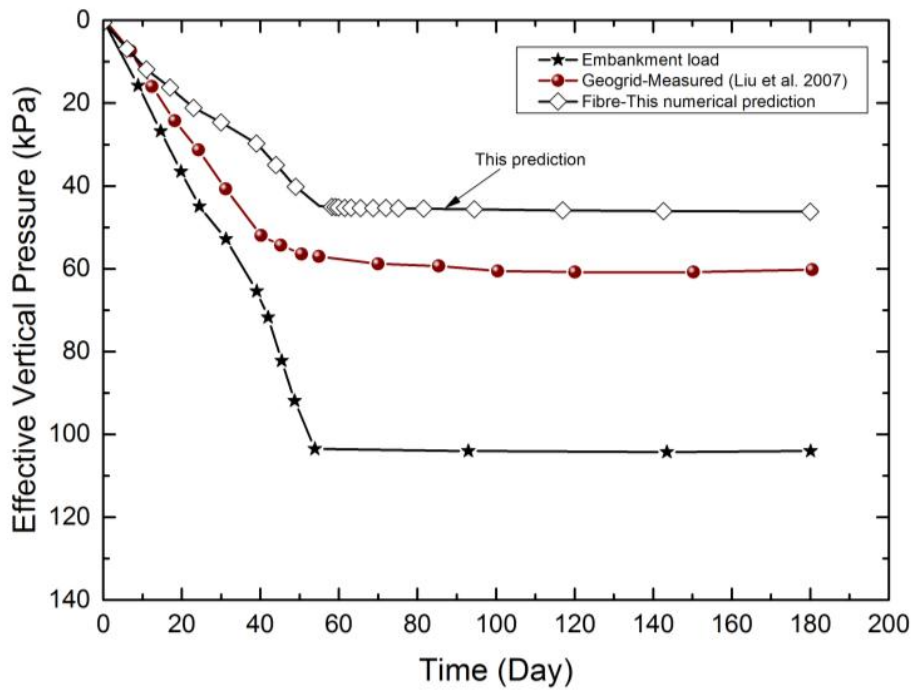

FIG. 3 Earth pressure acting on soil surface between piles

\section{ANALYSIS OF RESULTS AND DISCUSSION}

\section{Load Transfer to the Piles and Soft Soil}

FIG. 3 and FIG. 4 show the variation of computed vertical effective pressure acting on foundation soil and pile heads in this numerical prediction, respectively, when natural fibrelime reinforced load transfer platform (LTP) was used to support embankment over piles in comparison with the field measurement pressure of geogrid reinforced LTP previously reported by Liu et al. (2007). In general, an increase in the embankment height caused additional vertical pressure, known as embankment load increasing with time. It can be observed in these figures that when the embankment height increased to $5.6 \mathrm{~m}$ over a period of 55 days, an increase in the corresponding embankment load was $104 \mathrm{kPa}$, while the vertical pressure acting on foundation soil between piles was constantly less than that of embankment load. For example, the maximum computed pressure transferred to foundation soil plotted in FIG. 3 in this numerical analysis was about $45 \mathrm{kPa}$ at the end of embankment construction, which is roughly $43 \%$ of the embankment load and $79 \%$ of the measured pressure in the case of geogrid-reinforced embankment. However, the computed pressure transferred to pile heads significantly increased with the embankment load as presented in FIG. 4. For example, the maximum computed pressure acting on pile head in this numerical prediction at the completion of embankment construction was about $625 \mathrm{kPa}$, which is approximately 14 times greater than the pressure transferred to foundation soil and 6 times larger than the embankment load. This has a good agreement with the field measurement data 
previously presented by Liu et al. (2007) for the case of geogrid reinforced LTP. It can be noted that with the use of NFRLTP pile-supported embankment, the piles carried the major load of embankment due to soil arching effect. Thus, a relatively small embankment load was transferred to the foundation soil between piles.

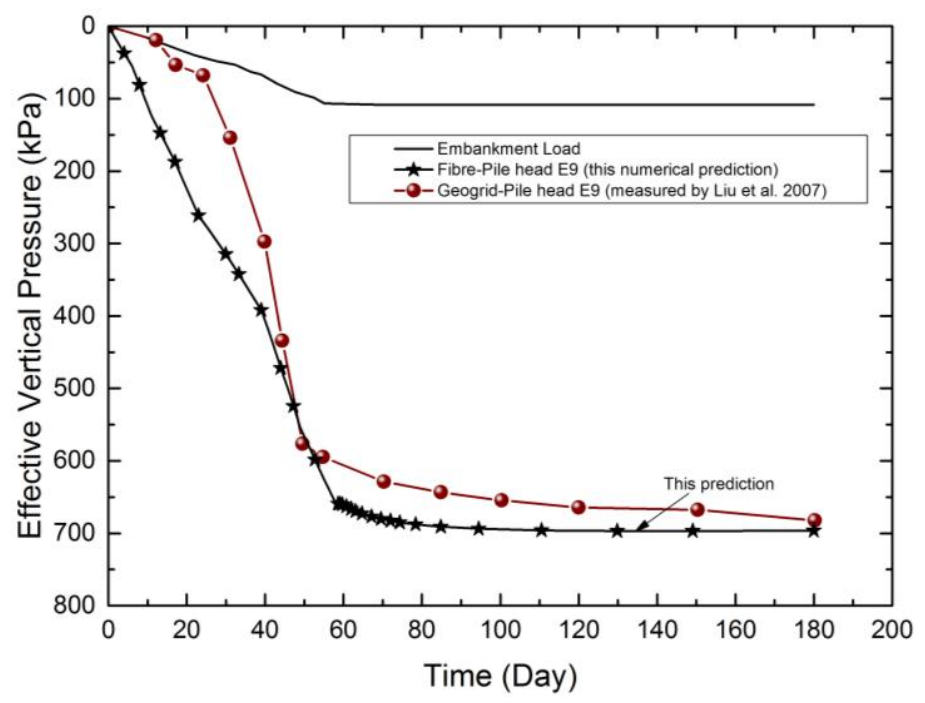

FIG. 4 Earth pressure acting on the top of reinforced concrete piles

In addition, FIG. 5 presents the comparison of stress reduction ratio (SRR) between fibrelime reinforced LTP and geogrid reinforced LTP with embankment height. The stress reduction ratio is defined as a ratio of average effective stress applied on foundation soil to the embankment load. Generally, the stress reduction ratio reduced with the increase in embankment height. The drop of SRR in cases of fibre-lime reinforced LTP was converged to value of 0.40 at the time of completion of embankment construction, which is in good agreement with the measured and computed values of SRR in case of geogrid-reinforced embankment reported by Liu et al. (2007). The lower stress reduction ratio redirects stress to the pile heads. This could be attributed to the higher relative stiffness of concrete piles to foundation soil. Furthermore, the decrease in the stress reduction ratio may be due to the higher internal friction angle and cohesion of fibre-lime reinforced load transfer platform contributing to the drop of SRR, but increase in efficacy of load transfer mechanism of NFRLTP pile-supported embankment as elaborated by Okyay \& Dias (2010).

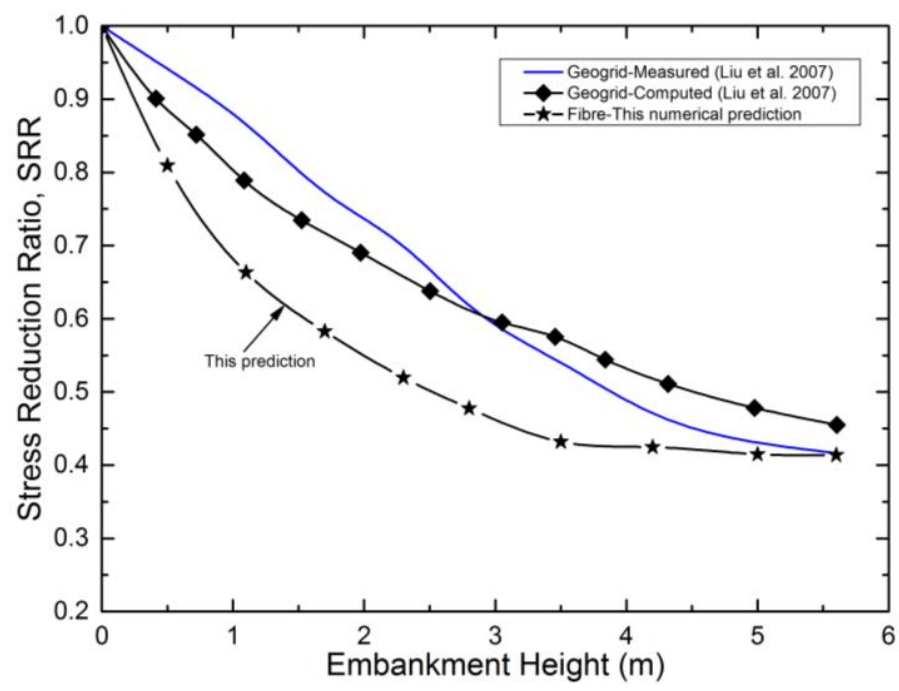

FIG. 5 Influence of embankment height on stress reduction ratio 


\section{Variation of excess pore water pressure}

FIG. 6 shows the variations of simulated excess pore water pressure (EPWP) with time in the soft silty clay stratum at $8.0 \mathrm{~m}$ depth (P2) under the embankment center for the case of fibre-lime reinforced LTP in comparison with both the computed and measured EPWP data previously reported by Liu et al. (2007) in case of geogrid reinforced LTP. As can be observed in the figure, the simulated excess pore water pressure in this numerical prediction reached its peak value of approximately $16 \mathrm{kPa}$ at the end of embankment construction and then dissipated almost $84 \%$ after 125 days of consolidation. As expected, there was a high increase in excess pore water pressure during the embankment construction process observed in both the numerical predictions and field measurements, which was associated with the staged construction of the embankment. Nonetheless, the maximum predicted excess pore water pressure for the case of fibre-lime reinforced LTP was only about $16 \mathrm{kPa}$ in the middle of soft silty clay since the embankment load was mainly transferred to piles. Moreover, the simulated dissipation in case of fibre-lime reinforced LTP was very fast compared to the measured excess pore water pressure in case of geogrid reinforced LTP, which may be attributed to the decrease in hydraulic conductivity of soft silty clay due to decrease in void ratio during the consolidation process that was not taken into account in this numerical analysis. Overall, the simulated excess pore water pressure generation and dissipation in case of fibre-lime reinforced load transfer platform and pile supported embankment agree well with the computed data previously reported by Liu et al. (2007) for the case of geogrid reinforced embankment. This indicates that fibre-lime treated soil can be successfully adopted as a load transfer platform.

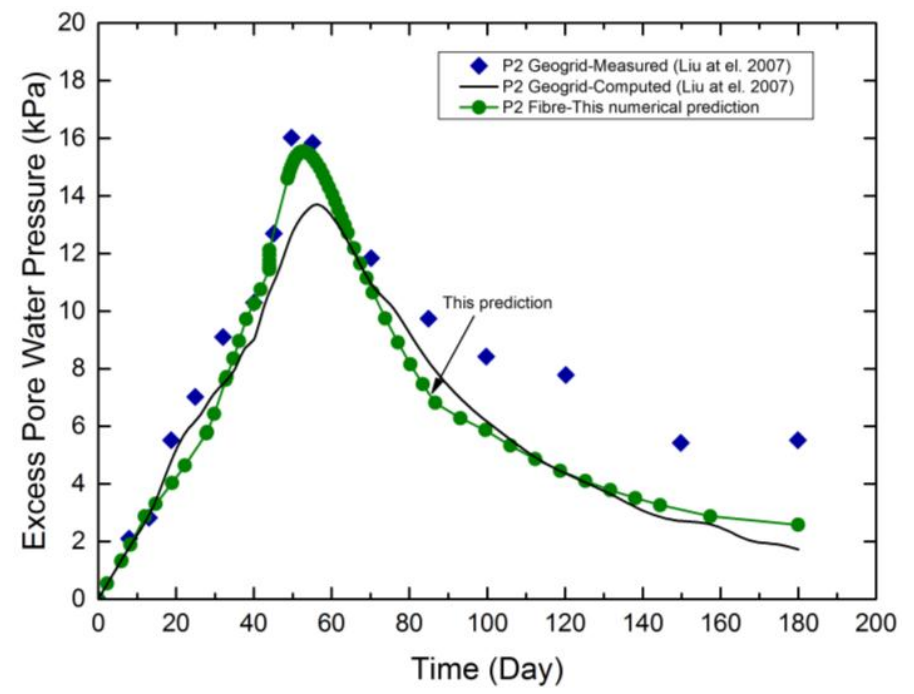

FIG. 6 Comparison between measured and computed excess pore water pressure

\section{CONCLUSIONS}

An equivalent 2D plane strain FEM model was utilised to investigate the mechanical behavior of fibre reinforced load transfer platform positioned on piles stabilising soft soil and variations of excess pore water pressure under the embankment load. Generally, an equivalent 2D model consumes less analysis time while produces results with reasonable accuracy.

It can be concluded that the application of natural fibre-lime reinforced load transfer platform reduces the embankment load transferred to soft soil between piles, hence curtailing the generation of excess pore water pressure in the soft soil stratum. Accordingly, the use of 
fibre reinforced platform under embankment prevents the total and differential settlement of the embankment. These demonstrates that the natural fibre-lime reinforced load transfer platform has comparable engineering characteristics as a geogrid reinforced LTP and can be widely used in engineering practice.

This numerical investigation indicates the importance of stiffness and shear strength parameters of fibre-lime reinforced load transfer platform consisting of the effective cohesion and the internal friction angle. It highlights that the shear resistance has a remarkable influence on load transfer mechanism between piles and surrounding soil and consequently settlement of the embankment.

\section{REFERENCES}

Anggraini, V., Asadi, A., Huat, B.B.K. \& Nahazanan, H. 2015, 'Performance of chemically treated natural fibre and lime in soft soil for the utilisation as pile-supported earth platform', International Journal of Geosynthetics and Ground Engineering, vol. 1, no. 3, pp. 1-14.

Cai, Y., Shi, B., Ng, C.W.W. \& Tang, C.-s. 2006, 'Effect of polypropylene fibre and lime admixture on engineering properties of clayey soil', Engineering Geology, vol. 87, no. 3-4, pp. 230-40.

Dang, L., Hasan, H., Fatahi, B. \& Khabbaz, H. 2015, 'Influence of bagasse ash and hydrated lime on strength and mechanical behaviour of stabilised expansive soil', GEOQuébec 2015, eds Côté \& Allard, Québec City, Canada, pp. 1-8.

Fatahi, B., Khabbaz, H. \& Fatahi, B. 2012, 'Mechanical characteristics of soft clay treated with fibre and cement', Geosynthetics International, vol. 19, pp. 252-62.

Fatahi, B., Basack, S., Premananda, S. \& Khabbaz, H. 2012, 'Settlement prediction and back analysis of Young's modulus and dilation angle of stone columns', Australian Journal of Civil Engineering, vol. 10, no. 1, p. 67.

Fatahi, B., Le, T., Fatahi, B. \& Khabbaz, H. 2013, 'Shrinkage properties of soft clay treated with cement and geofibers', Geotechnical and Geological Engineering, vol. 31, no. 5, pp. 1421-35.

Han, J. \& Gabr, M. 2002, 'Numerical analysis of geosynthetic-reinforced and pile-supported earth platforms over soft soil', Journal of Geotechnical and Geoenvironmental Engineering, vol. 128, no. 1, pp. 44-53.

Liu, H., Ng, C. \& Fei, K. 2007, 'Performance of a geogrid-reinforced and pile-supported highway embankment over soft clay: case study', Journal of Geotechnical and Geoenvironmental Engineering, vol. 133, no. 12, pp. 1483-93.

Nguyen, L.D., Fatahi, B. \& Khabbaz, H. 2014, 'A constitutive model for cemented clays capturing cementation degradation', International Journal of Plasticity, vol. 56, pp. 118.

Okyay, U.S. \& Dias, D. 2010, 'Use of lime and cement treated soils as pile supported load transfer platform', Engineering Geology, vol. 114, no. 1-2, pp. 34-44.

Parsa-Pajouh, A., Fatahi, B. \& Khabbaz, H. 2015, 'Experimental and numerical investigations to evaluate two-dimensional modeling of vertical drain-assisted preloading', International Journal of Geomechanics, vol. 0, no. 0, p. B4015003.

Sivakumar Babu, G.L., Vasudevan, A.K. \& Sayida, M.K. 2008, 'Use of coir fibers for improving the engineering properties of expansive soils', Journal of Natural Fibers, vol. 5, no. 1, pp. 61-75.

Tan, S., Tjahyono, S. \& Oo, K. 2008, 'Simplified plane-strain modeling of stone-column reinforced ground', Journal of Geotechnical and Geoenvironmental Engineering, vol. 134, no. 2, pp. 185-94. 